\title{
Smiling Response, Stranger Anxiety, and Autistic Disorder
}

\author{
Edward R. Ritvo
}

Published online: 20 July 2013

(C) Springer Science+Business Media New York 2013

\section{Letter to the Editor}

I would like to suggest that an enterprising young colleague conduct a series of experiments to explore the following hypotheses: One: Infants who develop autism spectrum disorder (ASD) have an absent, delayed, or modified "Smiling Response". Two: "Infants who develop ASD have an absent, delayed, or modified "Stranger Anxiety Response".

The background for this suggestion comes from a lecture I attended while a resident in psychiatry at the Boston Psychopathic Hospital, Harvard Medical School in 1958. Dr. Rene Spitz, the world-renowned Austrian psychologist and expert on infant development was presenting at Grand Rounds; (To the best of my recollection).

We were curious to determine the exact age at which the smiling response begins, peaks, and disappears. So my young associate and I leaned over the cribs of our little babies and smiled. To my chagrin, they consistently smiled at my young associate a few days earlier than at me, to me the Professor. How rude of them not to acknowledge the Professor first! But why we asked? Did we smile differently? To obviate this factor we took photographs of or faces and waved them over our infants. Still the same result, they smiled on average sooner at my young associate. Could it be the way we smelled or some other clue we were giving off? To obviate this we placed our pictures on placards and waved them over the infants from a distance. Same result. The disrespectful

E. R. Ritvo $(\square)$

UCLA Medical School, Los Angeles, CA, USA

e-mail: eritvo@aol.com infants continued to honor my young associate with earlier smiles!!

Then we began to erase parts of our faces on the placards. We erased the cheeks, the eyes, the chin, the mouth, and the ears. No Change. But, Low and Behold, when we got to the hairline and eyebrows there was nothing to erase on my picture. As you can see, I am quite bald, with sparse eyebrows, but my young assistant had bushy hair and bushy eyebrows. Reducing the picture to just the hair line/eyebrows and nose left just the shape of the letter T. At this placard all the infants smiled at about the same early age. And we smiled! So, what we found is that is what human infants smile at first, what we first love, is not out mothers face but the configuration of a horizontal line on top of a vertical line, in other words, the letter $\mathrm{T}$ !

Documenting abnormalities in the Smiling Response and Stranger Anxiety Response would provide the earliest signs of Autistic Disorder, and set the stage for early interventions. High-risk populations of younger siblings of ASD subjects could easily be tested, as physical interventions are not required to obtain the essential data (Ritvo et al. 1989; Ozonoff et al. 2011).

\section{References}

Ozonoff, S., Young, G. S., Carter, A., Messinger, D., Yirmiya, N., Zwaigenbaum, L., et al. (2011). Recurrence risk for autism spectrum disorders: A Baby Siblings Research Consortium study. Pediatrics, 128(3), e488-95. doi:10.1542/peds.2010-2825. Epub 2011 Aug 15.

Ritvo, E. R., Jorde, L. B., Mason-Brothers, A., Freeman, B. J., Pingree, C., Jones, M. B., et al. (1989). The UCLA-University of Utah Epidemiologic Survey of Autism: Recurrence risk estimates and genetic counseling. American Journal of Psychiatry, 146(8), 1032-1036. 